\title{
Erythrocyte Separation Using Gravitational Field Flow Effect
}

\author{
Li-Zhen Huang, Yu-Ting Chu, Hsiharng Yang* \\ Graduate Institute of Precision Engineering, National Chung Hsing University, Taiwan \\ Email: ^hsiharng@nchu.edu.tw
}

How to cite this paper: Huang, L.-Z., Chu, Y.-T. and Yang, H. (2017) Erythrocyte Separation Using Gravitational Field Flow Effect. J. Biomedical Science and Engineering, 10, 232-242.

https://doi.org/10.4236/jbise.2017.105018

Received: March 23, 2017

Accepted: May 21, 2017

Published: May 24, 2017

Copyright () 2017 by authors and Scientific Research Publishing Inc. This work is licensed under the Creative Commons Attribution International License (CC BY 4.0).

http://creativecommons.org/licenses/by/4.0/

\begin{abstract}
This research aims to simulate a gravity flow fractionation-the process to fractionate erythrocytes through gravitational field using ANSYS simulation software. A particular microfluidic channel was designed as a separation device. The gravitational equilibrium conditions of the erythrocytes and gravitational field as the parameters were chosen, then deriving the erythrocytes' path through numerical simulations. After the actual analog measurements, there is no big difference between the flow velocity and the pressure under $+/-10 \%$ atmosphere condition. According to the simulation results, the particle with the size $8 \mu \mathrm{m}$ (similar to the erythrocyte size) can be separated to the outside channel and discharged from the collecting area, other particles with the size $9 \mu \mathrm{m}$ will stay in the fluid motion and can be collected in the final collection area for preservation. Through the analog analysis by using the software-ANSYS-Fluent, the complete flowing path of the particles and the feasibility of the Gravity-Flow Fractionation can be directly proven.
\end{abstract}

\section{Keywords}

Erythrocyte Separation, Gravity Effect, Flow Field Fractionation, Microfluidic Channels

\section{Introduction}

With the progress of science and technology, all biomedical devices are changed rapidly. Biosensors are not only new stars in the biotech industry, but also one of the most significant advances from the mid-1990s. Biosensors are novel products which combine physics, biology, electronics, chemistry, machinery with automatic control. At present, more and more industries have focused on the tiny devices study and applied in the biology and biochemistry fields. The key of the miniaturization technique is called Micro-Electro-Mechanical Systems (MEMS) 
which combines with semiconductor thin film process, mechanical and electrical integration and other precision technology. This technology integrates optoelectronics, machinery, electronics, chemicals, materials with biomedicine to miniaturize products and improves the performance while reducing manufacturing costs.

In 1990, Manz proposed a micro-total analysis system ( $\mu$-TAS) to achieve the main idea of a lab on achip [1] [2]. To implement biological chips, the initial design has to be planned completely for microfluidic system, which often includes micropumps [3], microvalves [4], micromixers [4] and other microfluidic components. The microfluidic process can be used to separate, dilute, filter, store, stop, [5] and quantify the microfluidics. To make the chip more efficient, the material or structure modification of chips according to the principle function of component is required. The effect of wafer size tends to be miniaturized and the miniaturization characteristic can also bring many advantages. In the future, the microfluidic systems will keep developing and the ultimate goal is to integrate all the analytical function of lab on a chip. In 2004, Lai et al. [6] published the use of Lab-on-a-CD. Microchannel is processed on CD and drove the microfluid by centrifugal force to mix the reagent. This can be applied to immunoassay [7] [8], cell sorting [9] [10] [11], toxicity analysis [12], protein detection [13] [14], AIDS detection [15] etc. and they have also been studied. However, the traditional detections depend on a variety of detection devices. Because the equipment occupies a large volume and it must be in a certain cleanliness environment which can be implemented. Therefore, microfluidic chips have a lot of advantages such as high sensitivity, high frequency response and high resolution due to the miniaturization of component size.

In addition, the experiment can utilize MEMS technology in mass production to reduce manufacturing cost. It is also hoped that the development of cheaper and disposable microfluidic wafers will avoid the problem of secondary contamination during the detection process and achieve the rapid analysis results. The microfludic channel design can carry out by the study of fluid and microstructure functionality. Red blood cells by gravitational field-flow fractionation were studied [16]. They investigated the influence of coulter counter which were studied in order to verify fractionation of red blood cells. The separation of red blood cell and plasma by using Zweifach-Fung effect and was experimentally demonstrated using simple microchannels [17]. By studying and simulating the motion of erythrocyte flow in bifurcating microfluidic channels via a low-dimensional model based on dissipative particle dynamics was studied [18]. Compared with the conventional electrophoretic and centrifugal separation blood methods, the proposed gravity-driven fluid can protect cells from being damaged. Using the analog simulation by the software-ANSYS-Fluent, the complete flowing path of the particles by analog simulation and determine the feasibility of the gravity-flow fractionation directly. The design can also be applied to biomedical research, blood and disease detection. It's anticipated to use the natural gravity to drive blood for erythrocyte cell separation by the correlation study. 


\section{Device Design and Simulation Tools}

The microfluidic channel device to separate erythrocytes through the gravitational field was designed by using the Solidwork software. It is a two-inlets flowing into a fractional microchannel with a particular microstructure (barrier) resulting the particles separation. The two-inlet ends are the buffer and blood injection ports. After injection, the liquid will flow into the inlet chamber and come out from the collection area due to the gravity impact. In addition, the microchannel had a barrier to separate the particles. The pore of barrier was designed by the trigonometric function, and the cosine law was used to find the angle and then apply to the Solidworks structure design. The cosine law of triangle could be obtained as Equation (1).

$$
c^{2}=a^{2}+b^{2}-2 a b \cos \cos (\gamma)
$$

This structure design simulates that the center of the curve and the barriers are triangle which the both sides are $16 \mathrm{~mm}$ in length and the bottom are $8 \mu \mathrm{m}$. The length of $8 \mu \mathrm{m}$ opposite to angle is $0.2865^{\circ}$ by the cosine theorem. The enlarged view of curve structure is shown in Figure 1. Once the design is determined, it is imported into ANSYS-CFX to simulate the flow velocity and pressure in the flow field inside the microchannel. Following to import the flow data into ANSYS Fluent, the numerical simulation for the particles separation may be obtained to determine the design feasibility.

\section{Simulation Analysis}

\section{a) Different gravity field effects}

The ANSYS-CFX was used to simulate the velocity and pressure of blood at different gravity fields. This experiment was set to be in the 1 atmosphere environment. Because the actual operation may be at different circumstances, so there was the additional $10 \%$ deviation consideration in the numerical simulation. The simulated results at the static flow field are shown in Figure 2. Three locations in the simulation are marked 1,2,3. The position 1 is before the fluid flow into the microfluidic channel which can show the initial state of fluid. The position 2 is the fluid flow into the middle of microfluidic channel which can show that fluid flow is into the channel after separation with the pressures

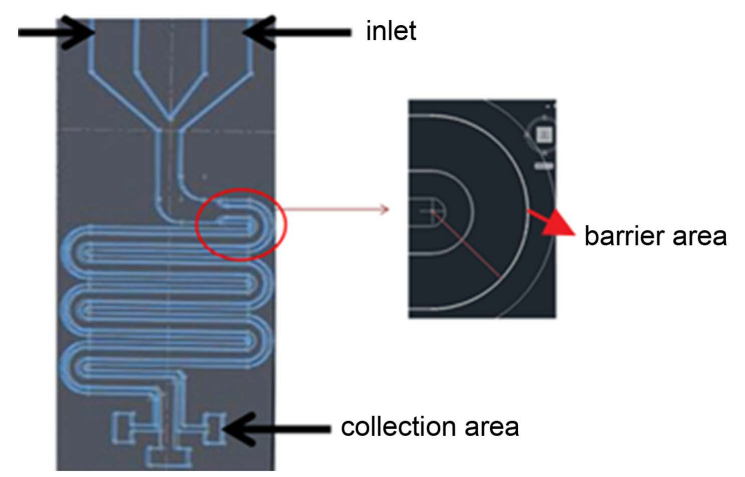

Figure 1. The blood separation device and its curved portion in the enlarged view. 


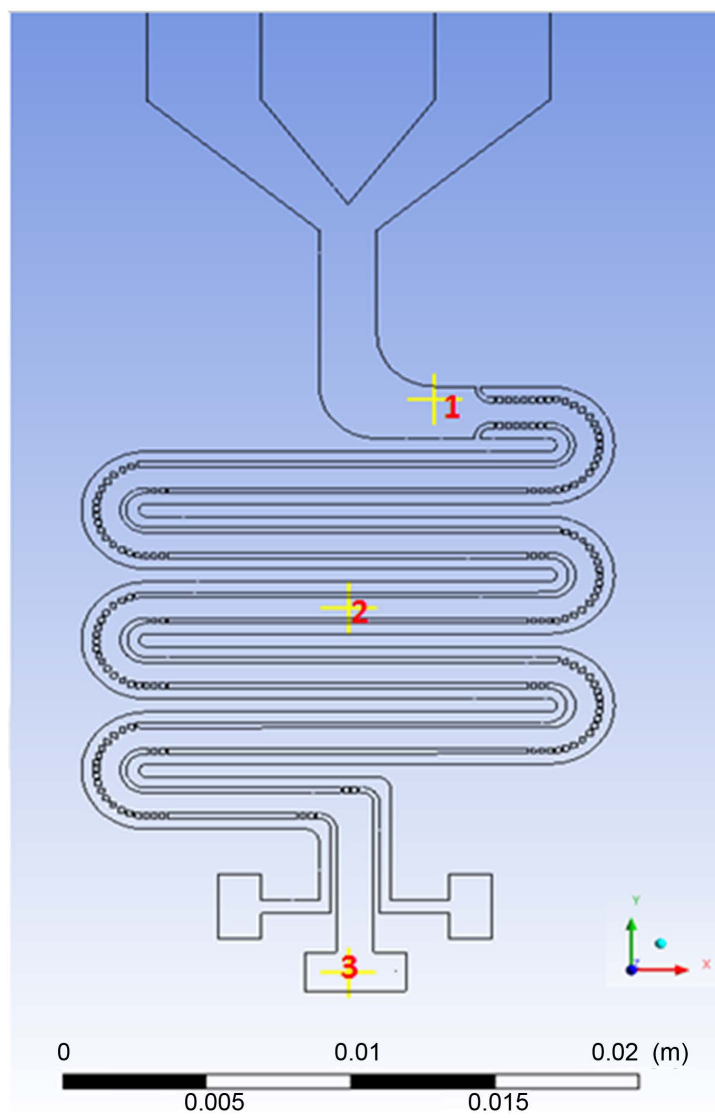

Figure 2. The analog flow channel design and the reference location diagram; 1 is the inlet location, 2 is the middle of the microfluidic channel, 3 is the outlet end.

change and flow rates. The position 3 is the reference point of the fluid in the final collection area which can show the pressure and velocity of final fluid collection after the separation.

\section{b) Flow rate simulation analysis at different atmospheric pressures}

According to the simulation results, the flow speed in each position is $\mathrm{p} 1=1.81$ $\mathrm{cm} / \mathrm{s}, \mathrm{p} 2=2.4 \mathrm{~cm} / \mathrm{s}$ and $\mathrm{p} 3=1.2 \mathrm{~cm} / \mathrm{s}$ at $1 \mathrm{~atm}$. and $\mathrm{p} 1=1.81 \mathrm{~cm} / \mathrm{s}, \mathrm{p} 2=2.46$ $\mathrm{cm} / \mathrm{s}, \mathrm{p} 3=1.3 \mathrm{~cm} / \mathrm{sat} 1.8 \mathrm{~atm}$., and $\mathrm{p} 1=1.8 \mathrm{~cm} / \mathrm{s}, \mathrm{p} 2=2.4 \mathrm{~cm} / \mathrm{s}$ and $\mathrm{p} 3=1.3$ $\mathrm{cm} / \mathrm{s}$, at $1.1 \mathrm{~atm}$., respectively. It's realized that the flow velocity of Position 1 is slightly lower because the different inputs of the liquid mixed with each other. The flow speed in Position 2 is slightly higher because an increase in the flow speed occurs simultaneously with a decrease in pressure according to Bernoulli's principle states. The flow speed in Position 3 is slightly lower due to the depletion of kinetic energy of the fluid after driven by the gravity and the output is set to open which contacts with outside atmosphere. Therefore; the flow rate is slightly lower than inside channel. In this study, it is found that the pressure difference within the range is less than $+/-10 \%$ variation of the atmospheric pressure, and there is no significant difference in the velocity between the corresponding locations. The simulated convergence of different atmospheric pressure is shown in Figures 3(a)-(c). The simulations of flow velocity at different atmospheric pressures are shown in Figures 4(a)-(c). 


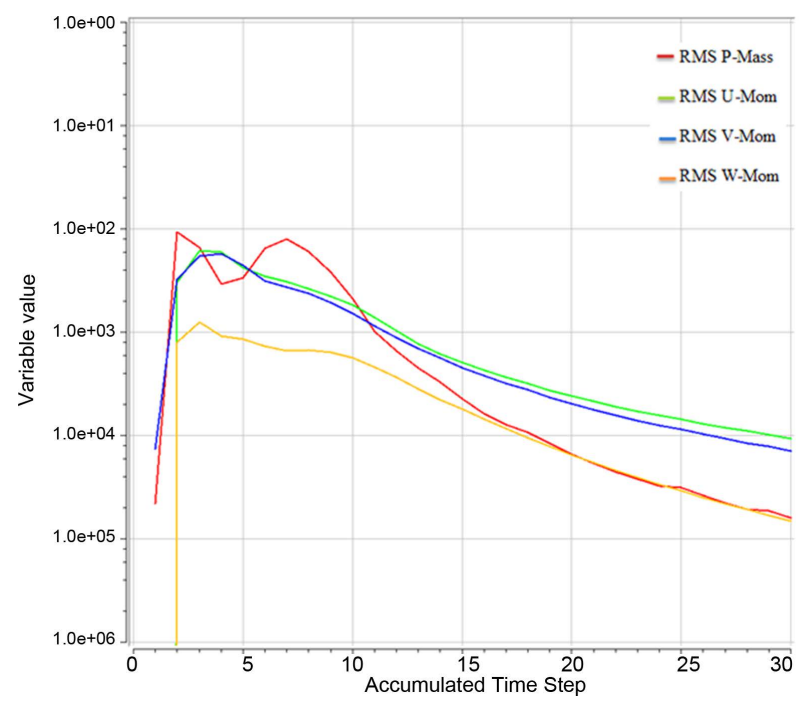

(a)

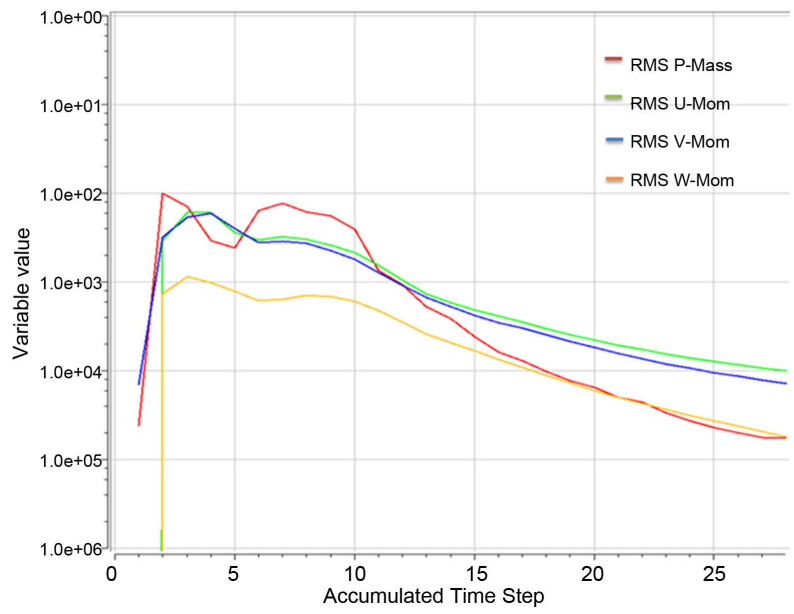

(b)

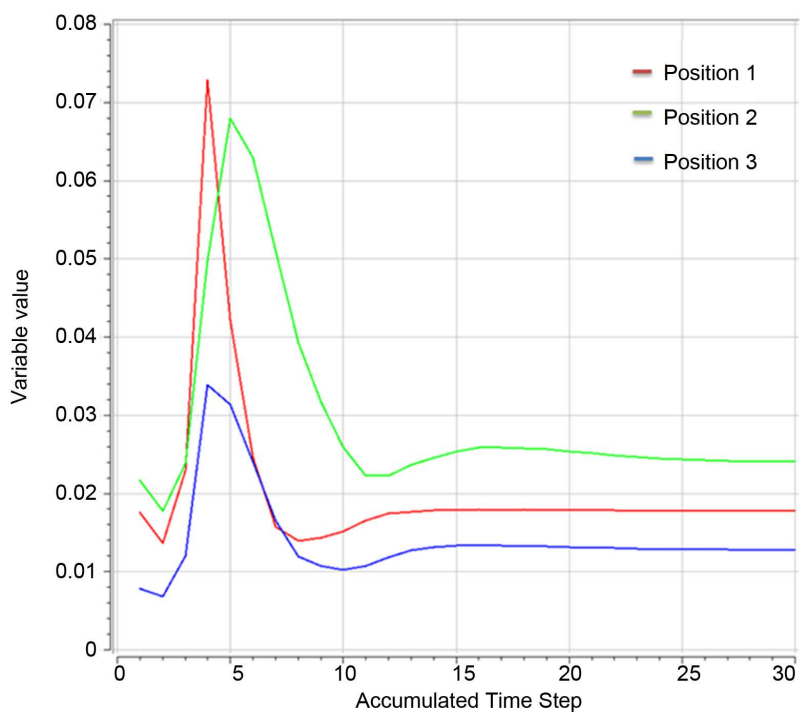

(c)

Figure 3. Simulated convergence at different atmospheric pressure; (a) 0.9 ; (b) 1.0 ; (c) 1.1 atmospheric pressure. 


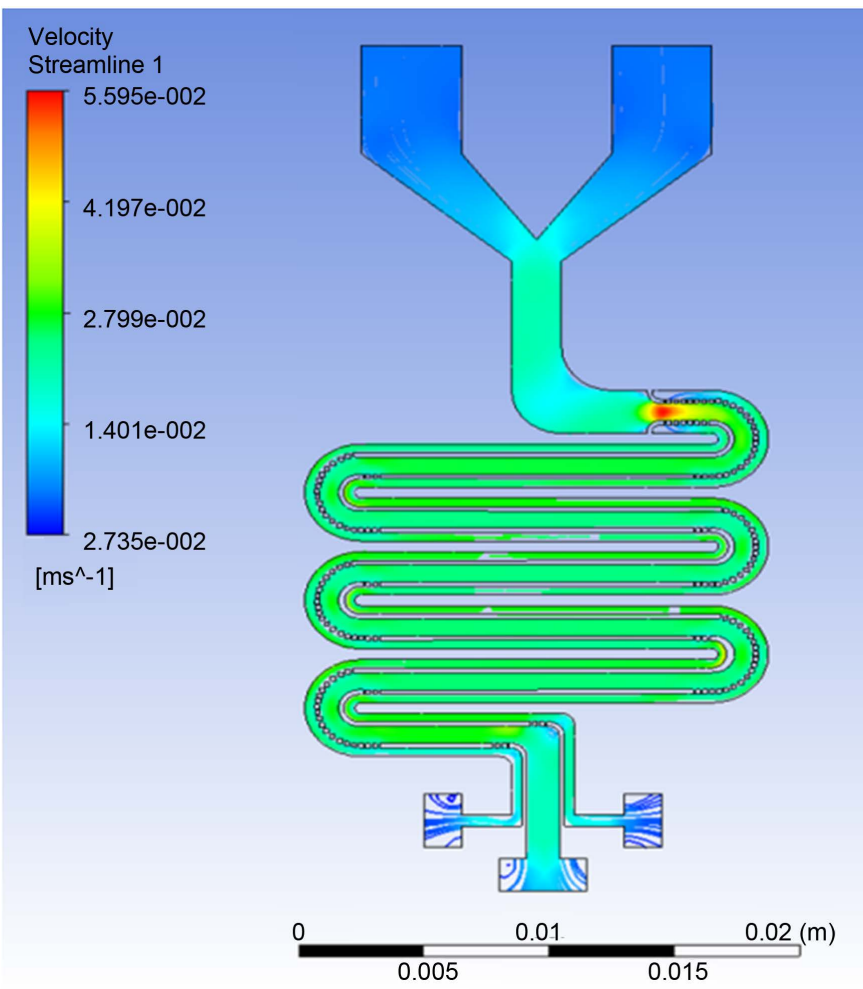

(a)

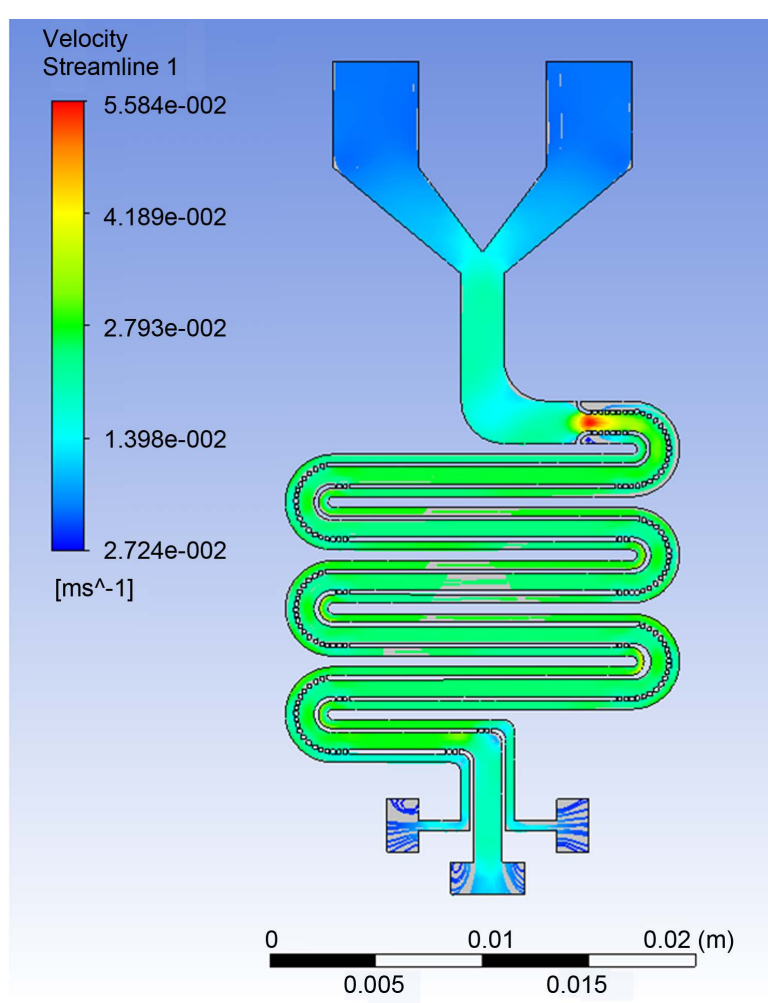

(b)

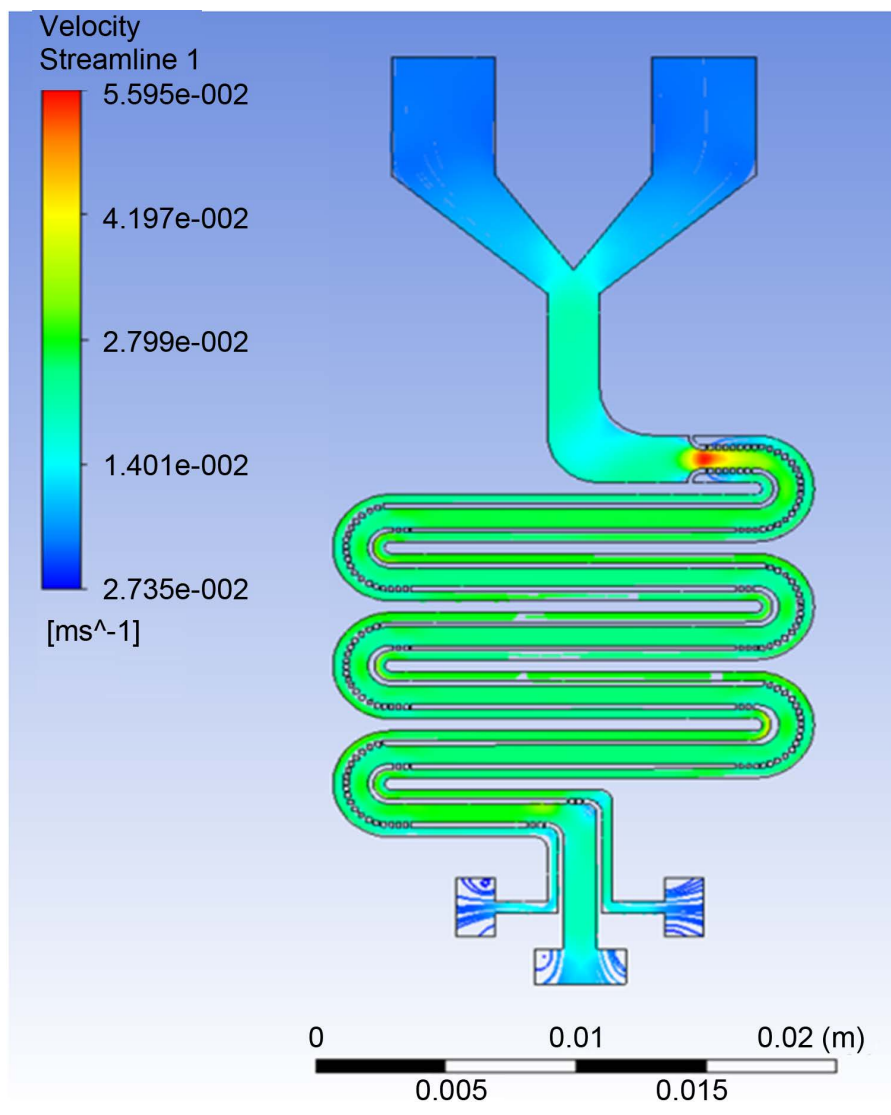

(c)

Figure 4. Simulated flow velocity at different atmospheric pressure; (a) 0.9; (b) 1.0; (c) 1.1 atmospheric pressure. 
c) Inside channel pressure analysis at different atmospheric pressure

According to the simulation, it can be seen that the pressures of $\mathrm{p} 1, \mathrm{p} 2$ and $\mathrm{p} 3$ are 62.44, 27.86 and $0 \mathrm{~Pa}$ relative to $1 \mathrm{~atm}$. Note for $1 \mathrm{~atm}$. is equal to $1.01325 \mathrm{~Pa}$. As a result, the pressure at the inlet end is high because the blood and the buffer collide with each other at the inlet of the microchannel. Therefore, the pressure at $\mathrm{p} 1$ is highest. According to Bernoulli's principle, the flow velocity increases and then the pressure is slightly reduced, thus the pressure of $\mathrm{p} 2$ is slightly less than the pressure of inlet end. The output is set to open, which contacts with outside atmosphere. So the pressure of $\mathrm{p} 3$ is 0 (same as the atmosphere).In this study, it is found that the pressure difference was less than $+/-10 \%$ variation of the atmospheric pressure, which did not have big difference from that of the corresponding points. The pressure in this range didn't affect the internal flow path. The pressure diagrams at different atmospheric pressures are shown in Figures 5(a)-(c).

\section{d) Particle separation behavior simulation}

The human capillary diameters are about $4-9 \mu \mathrm{m}$ which are numerous in the whole body and the main function is beneficial to the material exchange between the blood and the organization. The differences in the flow velocity with different density ratios and then perform the simulation referred to the human blood data were studied. The simulation started to inject 50,000 particles with $8 \mu \mathrm{m}$ in diameter and 500 particles with $9 \mu \mathrm{m}$ in diameter. The simulation parameters are shown in Table 1. The particles distribution behavior is shown in Figure 6. The inlet end and outlet end of the partial magnification are shown in Figure 6(b) and (c). It's obviously shown, different particles came out to different outlets. The desired separation results are achieved by using this device.

\section{Conclusion}

The gravitational field separation by using the design microfluidic channel is able to separate microparticles in microchannels and simulated to be erythrocyte separation in blood. By using 0.9, 1, 1.1 atm. Environments to investigate the effect on the microfluidic channel, it can be seen clearly that there is no difference between the flow velocity or the pressure inside the internal flow under the normal environment through reference points of inlet end and outlet end of fluid. It is found that is no significant effect on the flow field, and the difference is

Table 1. Parameters for the particles simulation.

\begin{tabular}{cc}
\hline Project & Value \\
\hline Velocity $(\mathrm{m} / \mathrm{s})$ & 0.05 \\
Min. diameter $(\mu \mathrm{m})$ & 8 \\
Max. diameter $(\mu \mathrm{m})$ & 9 \\
Mean. diameter $(\mu \mathrm{m})$ & 8.5 \\
Spread factor & 20 \\
Density $\left(\mathrm{g} / \mathrm{cm}^{3}\right)$ & 1.098 \\
\hline
\end{tabular}




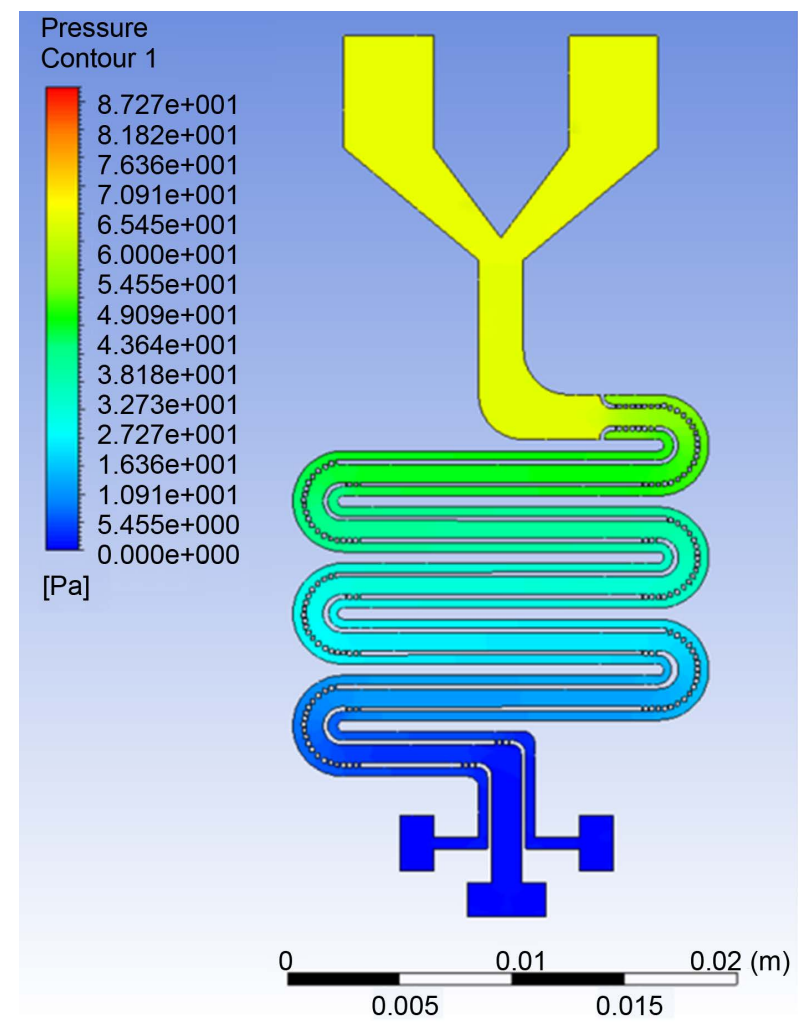

(a)

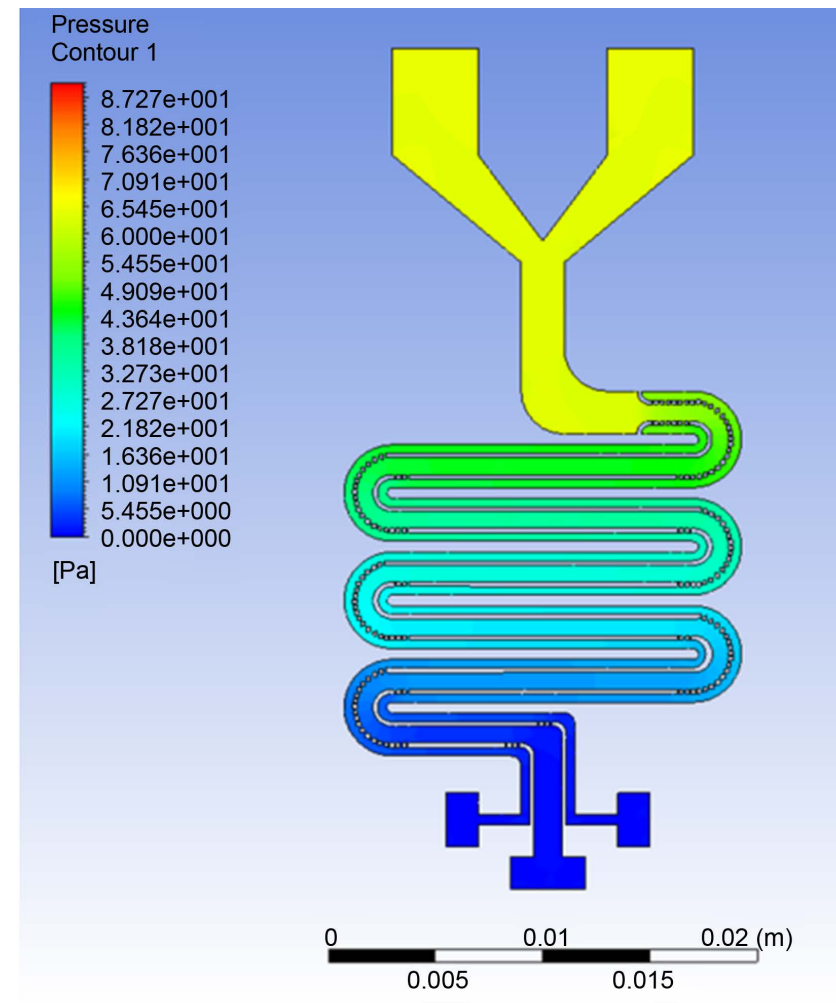

(b)

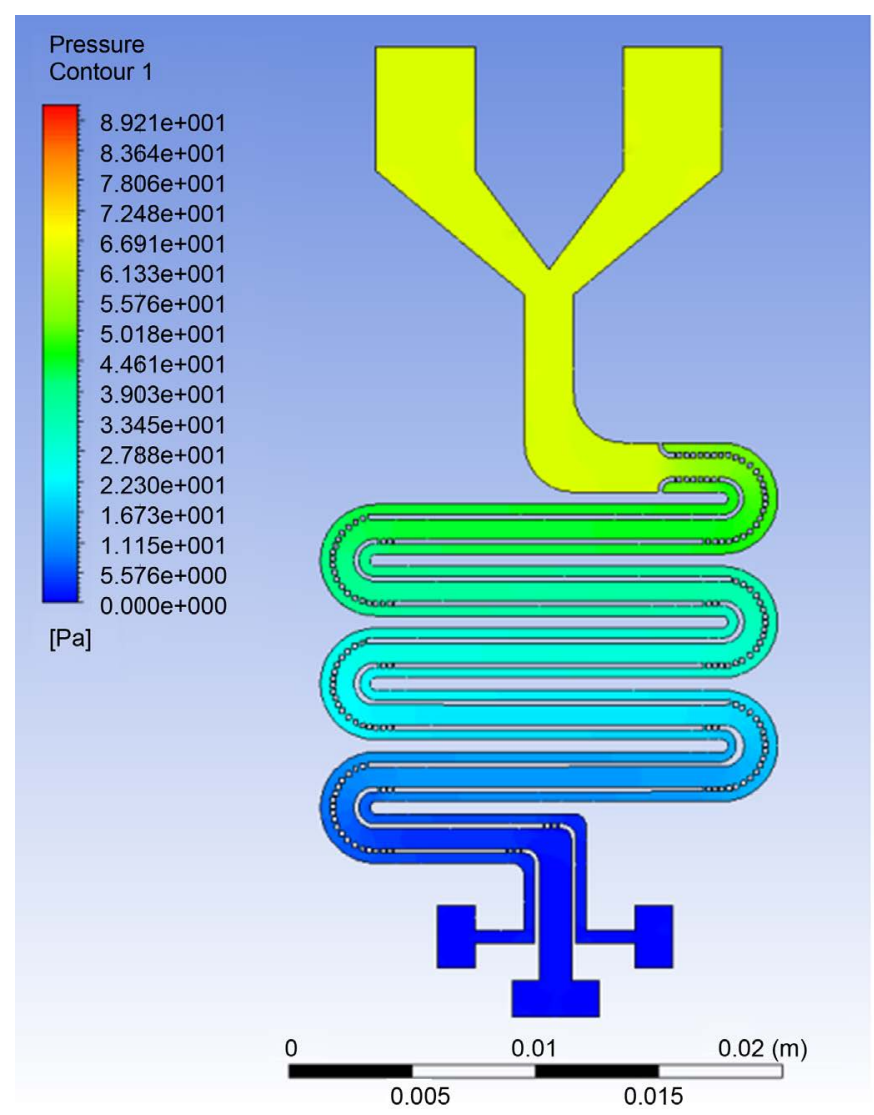

(c)

Figure 5. The inside channel pressures at different atmospheric pressure; (a) 0.9; (b) 1.0; (c) 1.1 atmospheric pressure. 


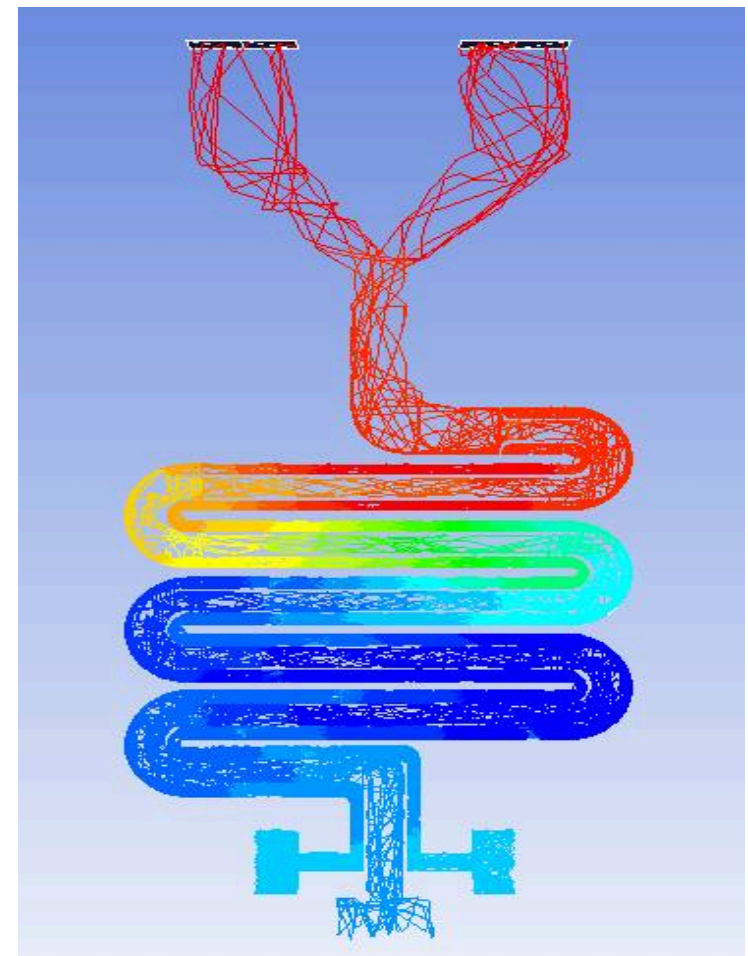

(a)

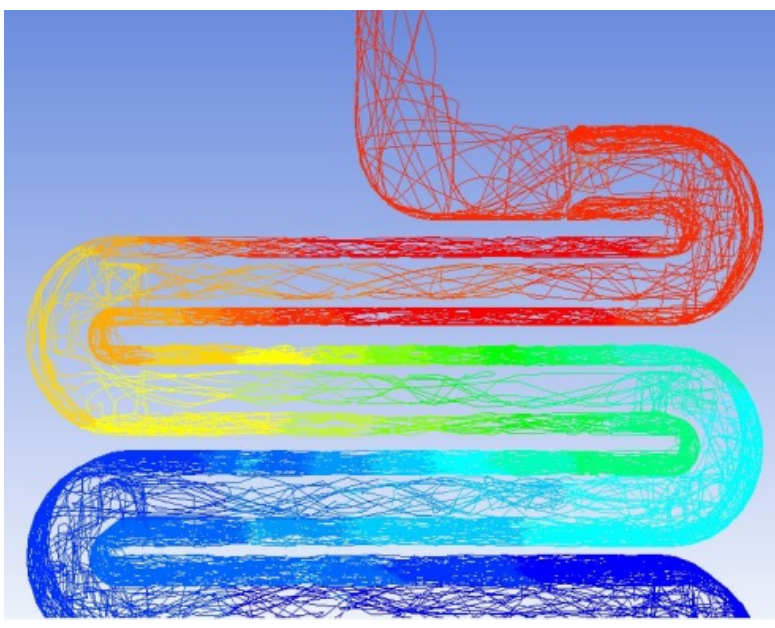

(c)

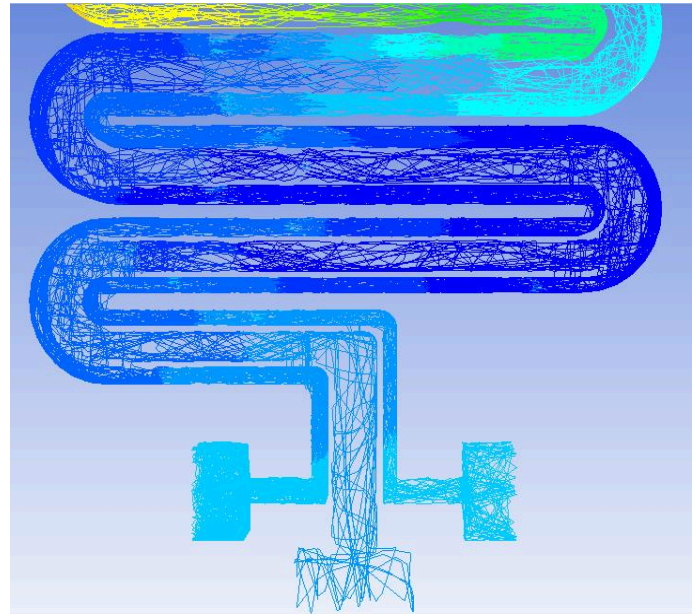

(d)

Figure 6. The particle separation flow diagram; (a) overview; and the partial magnification view: (b) the inlet end and (c) outlet end.

less than $1 \%$ under $+/-10 \%$ variation condition. According to the simulation results, the particle with $8 \mu \mathrm{m}$ in diameter can be separated to the outside channel and discharged from the collecting area. The particle with $9 \mu \mathrm{m}$ in diameter still can be kept in the fluid motion and can be collected in the final collection area for preservation. The microfluidic channel design for erythrocyte separation is feasible from the simulation study.

\section{Acknowledgment}

This work was supported by the Ministry of Science and Technology of Taiwan 
(Grant no. MOST105-2923-M-005-001-MY3).

\section{References}

[1] Manz, A., Graber, N. and Widmer, H.M. (1990) Miniaturized Total Analysis Systems: A Novel Concept for Chemical Sensing. Sensors and Actuators B: Chemical, 1, 244-248.

[2] Vandelli, N., Wroblewski, D., Velonis, M. and Bifano, T. (1998) Development of a MEMS Microvalve Array for Fluid Flow Control. Journal of Microelectromechanical Systems, 7, 395-403. https://doi.org/10.1109/84.735347

[3] Yun, K.S., Cho, I.J., Bu, J.U., Kim, C.J. and Yoon, E. (2002) A Surface-Tension Driven Micropump for Low-Voltage and Low-Power Operations. Journal of Microelectromechanical Systems, 11, 454-461. https://doi.org/10.1109/JMEMS.2002.803286

[4] Yang, Z., Matsumoto, S., Goto, H., Matsumoto, M. and Maeda, R. (2001) Ultrasonic Micromixer for Microfluidic System. Sensors and Actuators A: Physical, 93, 266272.

[5] Lai, S., Wang, S., Luo, J., Lee, L.J., Yang, S.T. and Madou, M.J. (2004) Design of a Compact Disk-Like Microfluidic Platform for Enzyme-Linked Immunosensor Assay. Analytical Chemistry, 76, 1832-1837. https://doi.org/10.1021/ac0348322

[6] Harald, B.S. (2004) Flow Cytometer for Measurement of the Light Scattering of Viral and Other Submicroscope Particles. Cytometry Part A, 57A, 94-99.

https://doi.org/10.1002/cyto.a.10115

[7] Clain, M.A., Culbertson, C.T., Jacobson, S.C. and Ramsey, J.M. (2001) Flow Cytometer of Escherichia coli on Microfluidic Devices. Analytical Chemistry, 73, 53345338. https://doi.org/10.1021/ac010504v

[8] Wolff, A., Nielsen, I.R.P., Larsen, U.D., Friis, P., Goranovic, G., Poulsen, C.R., Kutter, J.P., Kutter, P. and Telleman, P. (2003) Integrating Advanced Functionality in a Micro Fabricated High-Throughput Fluorescent-Activated Cell Sorter. Lab on a Chip, 3, 22-27. https://doi.org/10.1039/b209333b

[9] Dittrich, P.S. and Schwille, P. (2003) An Integrated Microfluidic System for Reaction, High-Sensitivity Detection, and Sorting Fluorescent Cells and Particles. Analytical Chemistry, 75, 5767-5774. https://doi.org/10.1021/ac034568c

[10] Poulsen, C.R., Cilbertson, C.T., Jacobson, S.C. and Ramsey, J.M. (2005) Static and Dynamic Acute Cytotoxicity Assays on Microfluidic Devices. Analytical Chemistry, 77, 667-672. https://doi.org/10.1021/ac049279i

[11] Valero, A., Braschler, T., Demierre, N. and Renaud, P. (2010) A Miniaturized Continuous Dielectrophoretic Cell Sorter and Its Applications. Biomicrofluidics, 4, Article ID: 022807. https://doi.org/10.1063/1.3430542

[12] Bousse, L., Mouradian, S., Minalla, A., Williams, K. and Dubrow, R. (2001) Protein Sizing on a Microchip. Analytical Chemistry, 73, 1207-1212.

https://doi.org/10.1021/ac0012492

[13] Figeys, D. and Pinto, D. (2001) Proteomics on a Chip Promising Developments. Electrophoresis, 22, 208-216. https://doi.org/10.1002/1522-2683(200101)22:2<208::AID-ELPS208>3.0.CO;2-O

[14] Krishnan, M. (2004) Reactions and Fluidics in Miniaturized Natural Convection Systems. Analytical Chemistry, 76, 6254-6265. https://doi.org/10.1021/ac049323u

[15] Burns, M.A. (1998) An Integrated Nanoliter DNA Analysis Device. Science, 282, 484-487. https://doi.org/10.1126/science.282.5388.484 
[16] Urbfinkovfi, E., Vacek, A., Novakova, N., Matulik, F. and Chmelik, J. (1992) Investigation of Red Blood Cell Fractionation Gravitational Field-Flow by Fractionation. Journal of Chromatography, 583, 27-34.

[17] Yang, S., Undar, A. and Zahn, J.D. (2006) A Microfluidic Device for Continuous, Real Time Blood Plasma Separation. Lab on a Chip, 6, 871-880.

https://doi.org/10.1039/B516401J

[18] Li, X., Popel, A.S. and Karniadakis, G.E. (2012) Blood-Plasma Separation in YShaped Bifurcating Microfluidic Channels: A Dissipative Particle Dynamics Simulation Study. Physical Biology, 9, Article ID: 026010.

https://doi.org/10.1088/1478-3975/9/2/026010

Submit or recommend next manuscript to SCIRP and we will provide best service for you:

Accepting pre-submission inquiries through Email, Facebook, LinkedIn, Twitter, etc. A wide selection of journals (inclusive of 9 subjects, more than 200 journals)

Providing 24-hour high-quality service

User-friendly online submission system

Fair and swift peer-review system

Efficient typesetting and proofreading procedure

Display of the result of downloads and visits, as well as the number of cited articles

Maximum dissemination of your research work

Submit your manuscript at: http://papersubmission.scirp.org/

Or contact jbise@scirp.org 